\title{
Determination of the Banned Phthalates in PVC Plastic of Toys by the Soxhlet Extraction-Gas Chromatography/Mass Spectrometry Method
}

\author{
Lina Huang, Zhongyong Liu, Lezhou Yi, Chonghua Liu \& Danhua Yang \\ Inspection and Quarantine Technology Center \\ Guangdong Entry-exit Inspection and Quarantine Bureau, Guangzhou 510623, China \\ Tel: 86-20-3829-0584Ｅ-mail: yilz@iqtc.cn
}

Received: January 7, 2011 Accepted: January 22, 2011 doi:10.5539/ijc.v3n2p169

The research is financed by the Science and Technology Plan Projects of Guangdong Province (No. 2008A060206024 \& No.2009B080701058). (Sponsoring information)

\begin{abstract}
A Gas Chromatography/ Mass Spectrometry method for the determination of six phthalates which are banned by European Union Regulation and USA CPSIA, in polyvinyl chloride (PVC) toys is studied in this article. The samples were extracted in six hours by Soxhlet extractor when using dichloromethane as the extracting agent, researched by orthogonal experiment. Using TIC (total ion chromatogram) and SIM (select ion monitor) of GC-MS to achieve phthalate's qualitative and quantitative determination, of which detection limit, accuracy and operating procedure are better than the standards in EN 14372:2004 clause 6.3.2 and ASTM D7083-04.
\end{abstract}

Keywords: Phthalate, Plasticizers, Toys, Orthogonal test, Soxhlet extraction, Gas chromatography/Mass spectrometry

\section{Introduction}

Phthalates have much toxicity such as carcinogenesis, teratogenesis, immunization failure, and reproduction failure, harming human liver and kidney, and the toys with this substance will seriously harm children's health.

Europe and USA begun to established strict standards and laws for the use of phthalates. For example, in ASTM F963-03, the using quantity of DEHP was strictly limited. In the Regulation (EU) No 1907/2006 (REACH) and USA CPSIA, DBP, BBP, DEHP, DNOP, DINP, and DIDP were limited in toys.

To strengthen the control of the quality of toy products and protect children's health, it is very important and meaningful to study the determination methods of plasticizers in PVC plastics.

The pretreatment method of plasticizers in PVC plastics generally used the ASTM D3421-75 (this method had been canceled in 1987) (ASTM D3421-75, 1975) for reference, but the time of using this method is too long, and this method is not environmental. In 2004, EN 14372:2004 (EN 14372:2004, 2004) and ASTM D7083-04 (ASTM D7083-2004, 2004) were issued, but only the GC-FID method was adopted in some literatures (Song, 2004, P. 286 \& S. C. Rastogi, 1998, P. 724-726) after that, and it only suits to analyze the phthalates without isomerides, and the LOD (limit of detection) is high. ST2002 of Japan (ST2002, 2002) is only used to test the migratory plasticizers. China also established corresponding recommended standards, such as GB/T 20388-2006 (Wang, 2004), but the test range only includes textiles, not the PVC plastics in toys, and this standard and some literatures (Tan, 2007, P. 133-135) adopted the ultrasonic extraction, and some methods used the high performance liquid chromatography (HPLC) (Chen, 2004, P. 61-64) or the microwave extraction method (Wang, 2008, P. 30-33), which all are largely different with the international standard methods such as Soxhlet extraction method and the gas chromatography/mass spectrometry.

\section{Experiment}

2.1 Key instruments

(1) Gas chromatography/mass spectrometer. USA Thermo Finnigan TraceMS Plus, with AS2000 Automatic Sample injector.

(2) Soxhlet extractor.

2.2 Key reagents

(1) Dichloromethane. Pure-class chromatography, product of Germany Meker Company. 
(2) DBP, CAS No. 84-74-2. Standard product of USA ChemService Company.

(3) BBP, CAS No. 85-68-7. Standard product of USA ChemService Company.

(4) DEHP, CAS No. 117-81-7. Standard product of USA ChemService Company.

(5) DNOP, CAS No. 117-84-0. Standard product of USA ChemService Company.

(6) DINP, CAS No. 28553-12-0. Isomeride mixture, standard product of Germany Dr.Ehrenstorfer Company.

(7) DIDP, CAS No. 26761-40-0. Isomeride mixture, standard product of Germany Dr.Ehrenstorfer Company.

\subsection{Experiment conditions}

(1) Chromatograph conditions. Chromatographic column: J\&W DB-5 capillary column $(15 \mathrm{~m} \times 0.25 \mathrm{~mm} \times 0.25$ $\mu \mathrm{m}$ ); Heating procedure: keep $1 \mathrm{~min}$ in $150^{\circ} \mathrm{C}$, and heat to $230^{\circ} \mathrm{C}$ by the speed of $30^{\circ} \mathrm{C} / \mathrm{min}$ and keep $0 \mathrm{~min}$, and heat to $260^{\circ} \mathrm{C}$ by the speed of $5^{\circ} \mathrm{C} / \mathrm{min}$ and keep $1 \mathrm{~min}$, and heat to $300^{\circ} \mathrm{C}$ by the speed of $20^{\circ} \mathrm{C} / \mathrm{min}$ and keep $5 \mathrm{~min}$; Gas (He) carrier flow rate: $1.2 \mathrm{~mL} / \mathrm{min}$, and the sample injection volume: $1.0 \mu \mathrm{L}$; the split ratio: 30:1.

(2) Mass spectrum conditions. Electron impaction (EI) ion source; electron energy $70 \mathrm{eV}$; the temperature of transmission line $280^{\circ} \mathrm{C}$, the temperature of ion source $230^{\circ} \mathrm{C}$; selected ions $\mathrm{m} / \mathrm{z} 149,293,297,307$; quality scanning range $\mathrm{m} / \mathrm{z}$ 50-500, collection time $3-12.5 \mathrm{~min}$, scanning time: $0.1 \mathrm{~s}$.

(3) Orthogonal test: use the three-factor-two-level $\mathrm{L}_{4}\left(2^{3}\right)$ orthogonal array to test the samples four times. Factor A: extraction solvent: tetrachloromethane + carbinol, dichloromethane; Factor B: extraction quality, 1g, 2g; Factor C: extraction time: 16 hours, 6 hours. Find out the influencing efficiencies of various factors on the phthalates in same positive PVC plastic samples, and confirm the optimal pretreatment condition by the Soxhlet extraction method.

(4) Final decided experiment method. Exactly weigh $1 \mathrm{~g}$ (precision: $1 \mathrm{mg}$ ), and put the test portions (below 5 $\mathrm{mm} \times 5 \mathrm{~mm}$ ) in the paper tube of $150 \mathrm{~mL}$ Soxhlet extractor, and add $120 \mathrm{~mL}$ dichloromethane in the $150 \mathrm{~mL}$ Florence flask, and extract the substances in $60^{\circ} \mathrm{C}-80^{\circ} \mathrm{C}$ for 6 hours, and the reflux times in one hour should exceed 4 . The remained substance about $120 \mathrm{~mL}$ is metered to $25 \mathrm{~mL}$ by dichloromethane, and is tested according to the conditions in GC-MS.

\section{Experiment results}

\subsection{Data analysis}

Perform the orthogonal test to the blue PVC plastic samples with DEHP and DINP in certain one toy according to the approaches in former chapter, and get the data (seen in Table 1).

(1) In 8 pieces of data, the best result is the experiment No. 3, i.e. weigh $1.0 \mathrm{~g}$ and use dichloromethane to extract phthalates for 6 hours.

(2) Compute the contribution coefficient $\mathrm{K}$ of various factors and levels, i.e. the average value of each level in the experiments. The contribution coefficient is bigger, and the level is better. From 12 values of $\mathrm{K}$, the optimal level is $\mathrm{A} 2 \mathrm{~B} 1 \mathrm{C} 2$, i.e. weigh $1.0 \mathrm{~g}$ and use dichloromethane to extract phthalates for 6 hours.

(3) Compute the range $\mathrm{R}$ of the contribution coefficients $\mathrm{K}$ of various factors, i.e. the difference between the maximum value and the minimum value of $\mathrm{K}$. The range is bigger, the factor is more important. From 6 values of $\mathrm{R}$, the factor influencing the extraction efficiency most is the extraction quality.

\subsection{Comparable test with standard method}

Compare the blue PVC plastic samples according to the optimal experiment conditions, ASTM D3421-75 and EN 14372:2004. The experiment result is in Table 2, and through tests, there is no significant difference among three methods.

\subsection{Precision of Soxhlet extraction method and labeling recovery test}

From different toy samples, take out various PVC materials to perform the precision and labeling recovery test. The accuracy is in $2 \%-7 \%$, and the labeling recovery rate is in $86 \%-103 \%$.

\subsection{LOD and linearity}

Perform the LOD test and the linear regression test for instruments. The chromatograms are seen in Figure 1-Figure 5, and the test result is in Table 3. The qualitative LOD of 6 kinds of plasticizer is in $0.05-.056 \mathrm{mg} / \mathrm{L}$, and the quantitative LOD of instruments is in $0.17-1.86 \mathrm{mg} / \mathrm{L}$, and the LOD of method is in $5-15 \mathrm{mg} / \mathrm{kg}$ (DBP, BBP, DEHP, DNOP) and $50 \mathrm{mg} / \mathrm{kg}$ (DINP, DIDP), which all satisfy the limitation requirement of $0.1 \%$ (i.e. $1000 \mathrm{mg} / \mathrm{kg}$ ). 


\subsection{Comparison and demonstration test among laboratories}

Organize 13 laboratories in 6 provinces in China (including the subordinate professional laboratories of various provincial and municipal entry-exit inspection and quarantine bureaus, the subordinate professional laboratories of Bureau of Quality and Technical Supervision, the professional laboratories with foreign capital backgrounds, and the subordinate laboratories of toy manufacturers) to perform the comparison and demonstration test among laboratories according to this method, and when the concentration range is in $100 \mathrm{mg} / \mathrm{kg}-150000 \mathrm{mg} / \mathrm{kg}$, the repeatable variation coefficient is in 3.1\%-7.1\%.

\section{Conclusions}

This method has following technical characteristics. (1) The qualitative accuracy of this method is better than ASTM D7083-2004. (2) By comparing with the diethyl ether in the extraction of EN 14372:2004, this method needs not to replace solvent when metering volume.

\section{References}

ASTM D7083-2004. (2004). Determination of Monomeric Plasticizers in Poly (Vinyl Chloride) (PVC) by Gas Chromatography. West Conshohocken: American Society for Testing and Materials.

ASTM D3421-75. (1975). Extraction and analysis of plasticizer mixtures from vinyl chloride plastics. West Conshohocken: American Society for Testing and Materials.

Chen, Minghui. (2004). Analysis of Phthalates in Cosmetics by HPLC-DAD. Journal of Instrumental Analysis. No. 23(4). P. 61-64.

EN 14372:2004. (2004). Child use and care articles-Cutlery and feeding utensils-Safety requirements and tests. Brussels: EUROPEAN COMMITTEE FOR STANDARDIZATION.

S. C. Rastogi. (1998). Gas chromatographic analysis of phthalate esters in plastic toys. Chromatographia. No. 47(11-12). P. 724-726.

Song, Xinping. (2004). Determining Eight Kinds of Plasticizer in PVC by the Gas Chromatography. Chinese Journal of Chromatography. No. 22(3). P. 286.

ST2002. (2002). Toy Safety Standard. Tokyo: The Japan Toy Association.

Tan, Jinhui. (2007). Study on Six Methods to Determine the Phthalate Compounds in Food-Package Plastic Products. Chinese Journal of Analysis Laboratory. No. 26(S1). P. 133-135.

Wang, Chengyun. (2008). Simultaneous determination of six kinds of restricted phthalates in PVC toys and childcare articles. Polyvinyl Chloride. No. 36(2). P. 30-33.

Wang, Mingtai. (2004). Determining the Phthalates in Textiles (GB/T 20388-2006). Beijing: China Standards Press.

Table 1. Orthogonal test results and computation analysis by the Soxhlet extraction method

\begin{tabular}{|c|c|c|c|c|c|}
\hline \multirow{4}{*}{ Test No. } & \multicolumn{5}{|c|}{ Factors } \\
\hline & Extracted solvent & Extracted mass & Extracted time & \multicolumn{2}{|c|}{ Result (mg/kg) } \\
\hline & \multicolumn{5}{|c|}{ Levels } \\
\hline & 1 & 2 & 3 & DEHP & DINP \\
\hline 1 & $\begin{array}{c}\text { Tetrachloromethane }+ \\
\text { carbinol }\end{array}$ & $1 \mathrm{~g}$ & 16 hours & 124329 & 9623 \\
\hline 2 & $\begin{array}{c}\text { Tetrachloromethane }+ \\
\text { carbinol }\end{array}$ & $2 g$ & 6 hours & 115260 & 9486 \\
\hline 3 & Dichloromethane & $1 \mathrm{~g}$ & 6 hours & 125144 & 9902 \\
\hline 4 & Dichloromethane & $2 \mathrm{~g}$ & 16 hours & 119252 & 9396 \\
\hline K1(DEHP) & 119794 & 124736 & 121790 & 1 & 1 \\
\hline K2(DEHP) & 122198 & 117256 & 120202 & 1 & 1 \\
\hline R(DEHP) & 2403 & 7480 & 1588 & 1 & 1 \\
\hline K1(DINP) & 9554 & 9762 & 9509 & 1 & 1 \\
\hline K2(DINP) & 9649 & 9441 & 9694 & 1 & 1 \\
\hline R(DINP) & 95 & 321 & 185 & 1 & 1 \\
\hline
\end{tabular}


Table 2. Validation test results $(\mathrm{mg} / \mathrm{kg})$

\begin{tabular}{|c|c|c|c|}
\hline Method & Qualification & DEHP & DINP \\
\hline $\begin{array}{c}\text { ASTM } \\
\text { D3421-75 }\end{array}$ & $\begin{array}{c}\text { Weigh up 1.0g sample, add Tetrachloromethane }+ \\
\text { carbinol (2:1), and Soxhlet extract for 16 hours }\end{array}$ & 124329 & 923 \\
\hline $\begin{array}{c}\text { EN 14372: } \\
2004\end{array}$ & $\begin{array}{c}\text { Weigh up 2.0g sample, add ethyl ether, and Soxhlet } \\
\text { extract for 6 hours }\end{array}$ & 121420 & 9129 \\
\hline $\begin{array}{c}\text { Soxhlet } \\
\text { extraction }\end{array}$ & $\begin{array}{c}\text { Weigh up 2.0g sample, add dichloromethane, and } \\
\text { Soxhlet extract for 6 hours }\end{array}$ & 902 \\
\hline
\end{tabular}

Table 3. Detection limit and linear correlation

\begin{tabular}{|c|c|c|c|c|c|c|}
\hline Test substance & DBP & BBP & DEHP & DNOP & DINP & DIDP \\
\hline Limit of Detection $(\mathrm{mg} / \mathrm{L})$ & 0.11 & 0.05 & 0.12 & 0.16 & 0.53 & 0.56 \\
\hline Limit of Quantitation $(\mathrm{mg} / \mathrm{L})$ & 0.36 & 0.17 & 0.40 & 0.53 & 1.76 & 1.86 \\
\hline Correlation & 0.9993 & 0.9997 & 0.9994 & 0.9996 & 0.9995 & 0.9994 \\
\hline Detection Limit of Method $(\mathrm{mg} / \mathrm{kg})$ & 10 & 5 & 10 & 15 & 50 & 50 \\
\hline
\end{tabular}

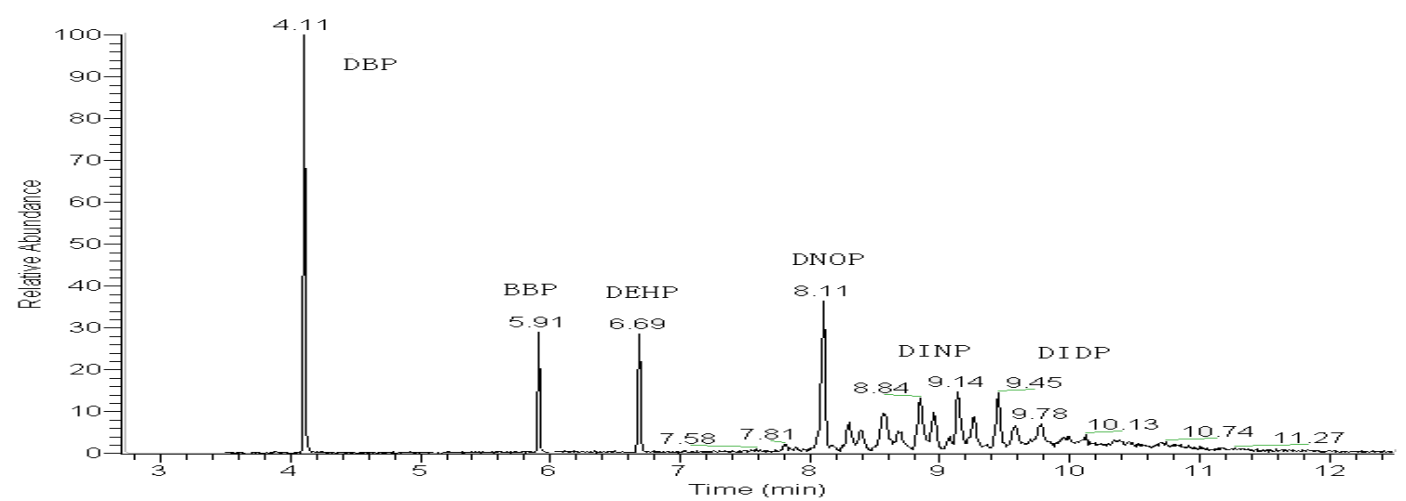

Figure 1. TIC of the six phthalates standard (DBP, BBP, DEHP, DNOP: $5 \mathrm{mg} / \mathrm{L}$, DINP, DIDP: 50mg/L)

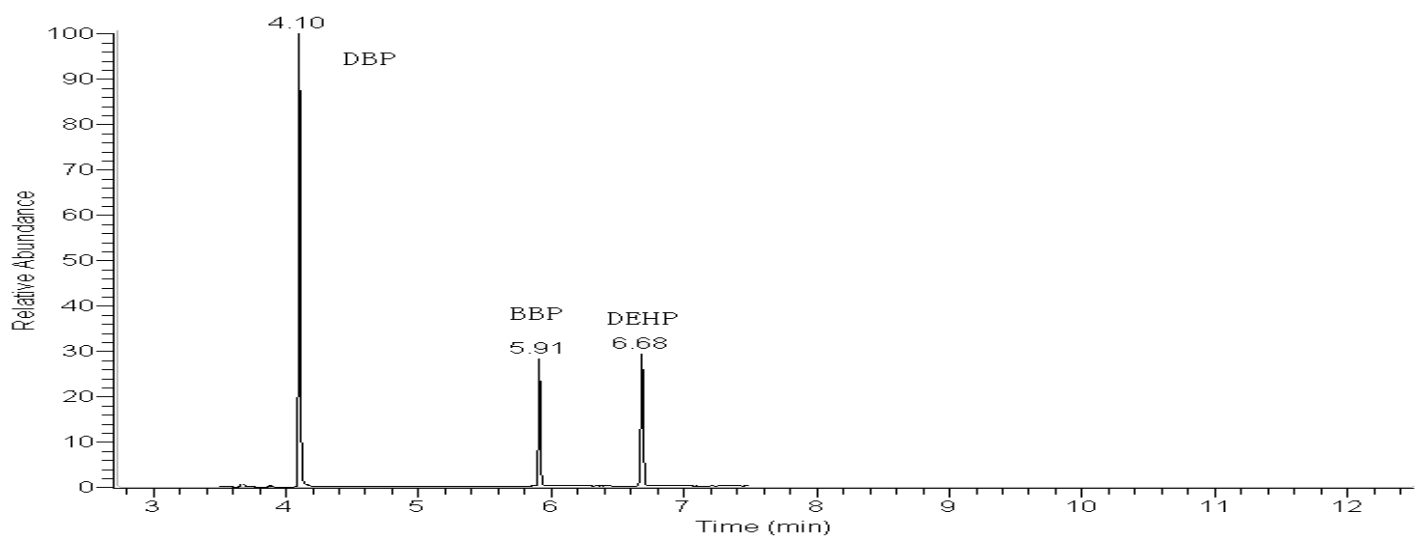

Figure 2. SIM of the DBP, BBP, DEHP Standard $(\mathrm{m} / \mathrm{Z}=149)$ 


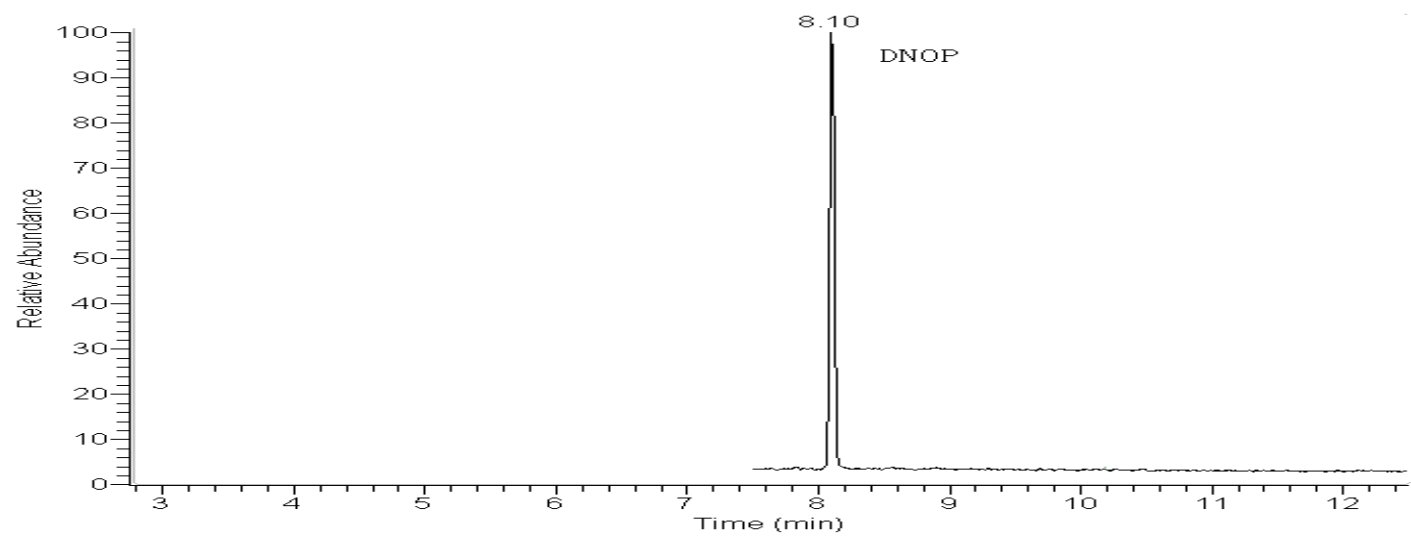

Figure 3. SIM of DNOP standard $(\mathrm{m} / \mathrm{Z}=279)$

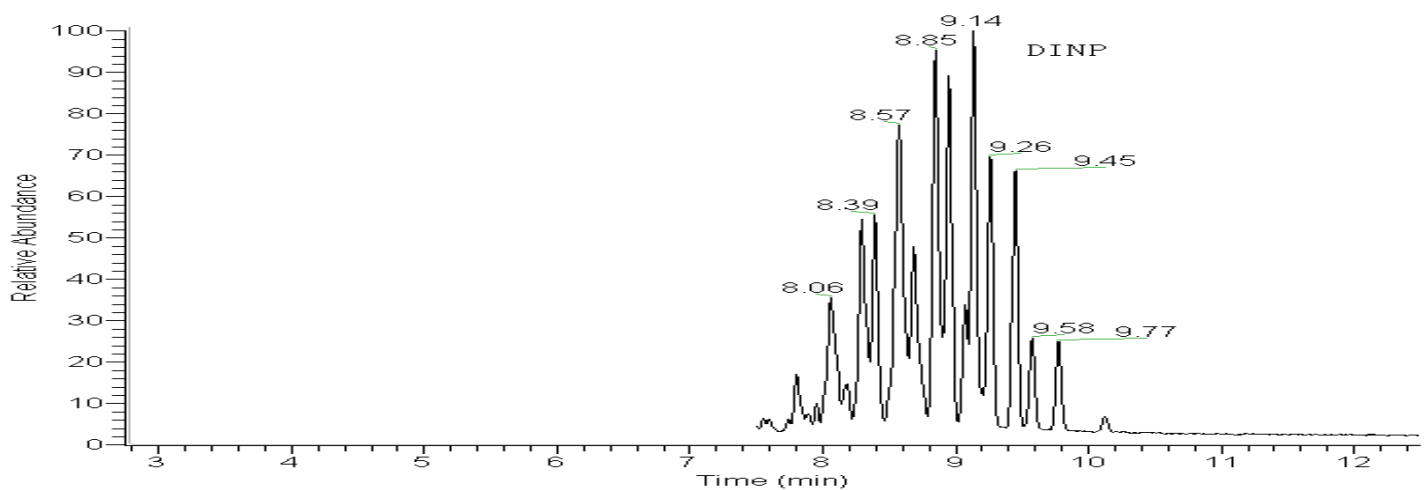

Figure 4. SIM of DINP standard $(\mathrm{m} / \mathrm{Z}=293)$

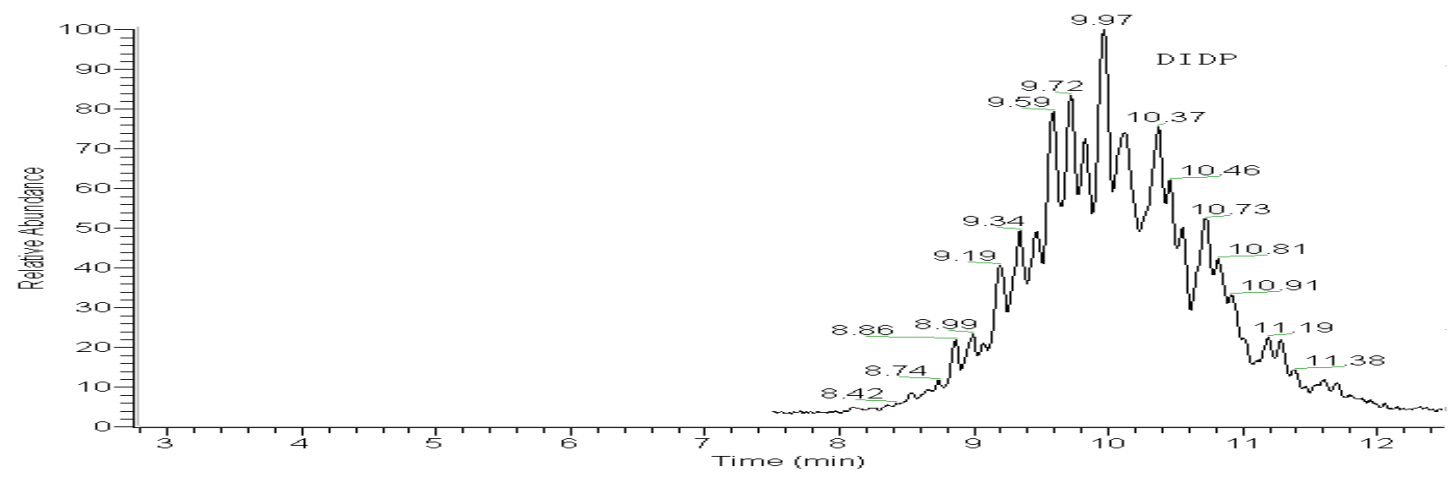

Figure 5. SIM of DIDP standard $(\mathrm{m} / \mathrm{Z}=307)$ 